\title{
IDENTIDAD CULTURAL, MEMORIA SOCIAL Y ARCHIVOS PARROQUIALES (SIGLOS XVIII-XIX): REFLEXIONES ETNOLÓGICAS A PARTIR DE UNA EXPERIENCIA EN BELÉN (ARICA, NORTE DE CHILE)
}

\author{
CULTURAL IDENTITY, SOCIAL MEMORY AND CHURCH RECORDS \\ (S. XVIII-XIX): ETHNOLOGICAL REFLECTIONS FROM AN \\ EXPERIENCE AT BELEN (ARICA, NORTHERN CHILE)
}

\author{
Francisca Urrutia Lorenzini ${ }^{*}$ Mauricio Uribe Rodríguez ${ }^{* *}$
}

\begin{abstract}
Este artículo se propone narrar el encuentro entre los conocimientos emanados desde las humanidades y las ciencias sociales con los saberes de la comunidad local, materializado a partir del caso de los Libros de la Parroquia de Belén (1763-1859). Se trata de un abordaje sobre los procesos de identidad cultural y memoria social que no solo integra las posturas convergentes, sino que también dialoga con las perspectivas divergentes y la complejidad propia del contexto actual en el marco de un proyecto de difusión. En particular, constituye una autocrítica desde la reflexión antropológica provocada gracias a este encuentro entre investigadores y una comunidad andina del norte de Chile en relación con un determinado archivo histórico.

Palabras claves: Libros parroquiales, identidad cultural, memoria social, comunidades locales, investigaciones universitarias, Belén.
\end{abstract}

This paper tells about the encounter between the knowledge that came from the social academic disciplines and the one generated by the local community, materialized at the Church Books of Belen (1763-1859). The attempt is to describe the dynamics of cultural identity and social memory that not only integrates convergent perspectives, but also dialogues with divergent points of view and the complexity of the current context in the frame of an outreach project. Particularly this constitutes a self-criticism from an anthropological reflection provoked thanks to this encounter between the academics and an Andean community of the northern Chile in relation with a certain historic archive.

Key words: Church Records, cultural identity, social memory, local communities, academic research, Belén.

\section{Introducción}

Este escrito nace a partir del proyecto "Los Libros de la Parroquia de Belén, reflexiones interculturales respecto a los temas de población, familia y comunidad"1, el que a su vez se desprende de una investigación doctoral que utilizó como fuente principal los registros de bautizo, matrimonio y defunciones de la Parroquia de Belén (1763-1859), Región de Arica y Parinacota, Norte de Chile (Figura 1$)^{2}$. En esta oportunidad pretendemos indagar sobre los procesos de identidad cultural y de memoria social que se articularon cuando la población beleneña se enfrentó a los registros parroquiales, cuya actual locación dentro del Archivo Nacional en Santiago era desconocida por ellos (Figura 2). En particular, esta experiencia se enmarca en aquella premisa fundamental respecto de la relación permanente que debiera existir entre la investigación científica y las comunidades contemporáneas que sustentan dichos estudios.

La emergencia de los estudios decoloniales, culturales, poscoloniales y subalternos durante la gran efervescencia crítica de las décadas de 1980 y 1990, retoma y denuncia la "colonialidad del poder" que cruza cualquier relato sobre el pasado y sus usos (p. ej., Abercrombie 2006 [1998], Boccara 2013, Fanon 2003 [1973], Foucault

\footnotetext{
* Universidad de Tarapacá, Arica, Chile. Santiago, Chile. Correo electrónico: solinaria@ gmail.com

** Universidad de Chile, Santiago. Correo electrónico: mur@uchile.cl
} 


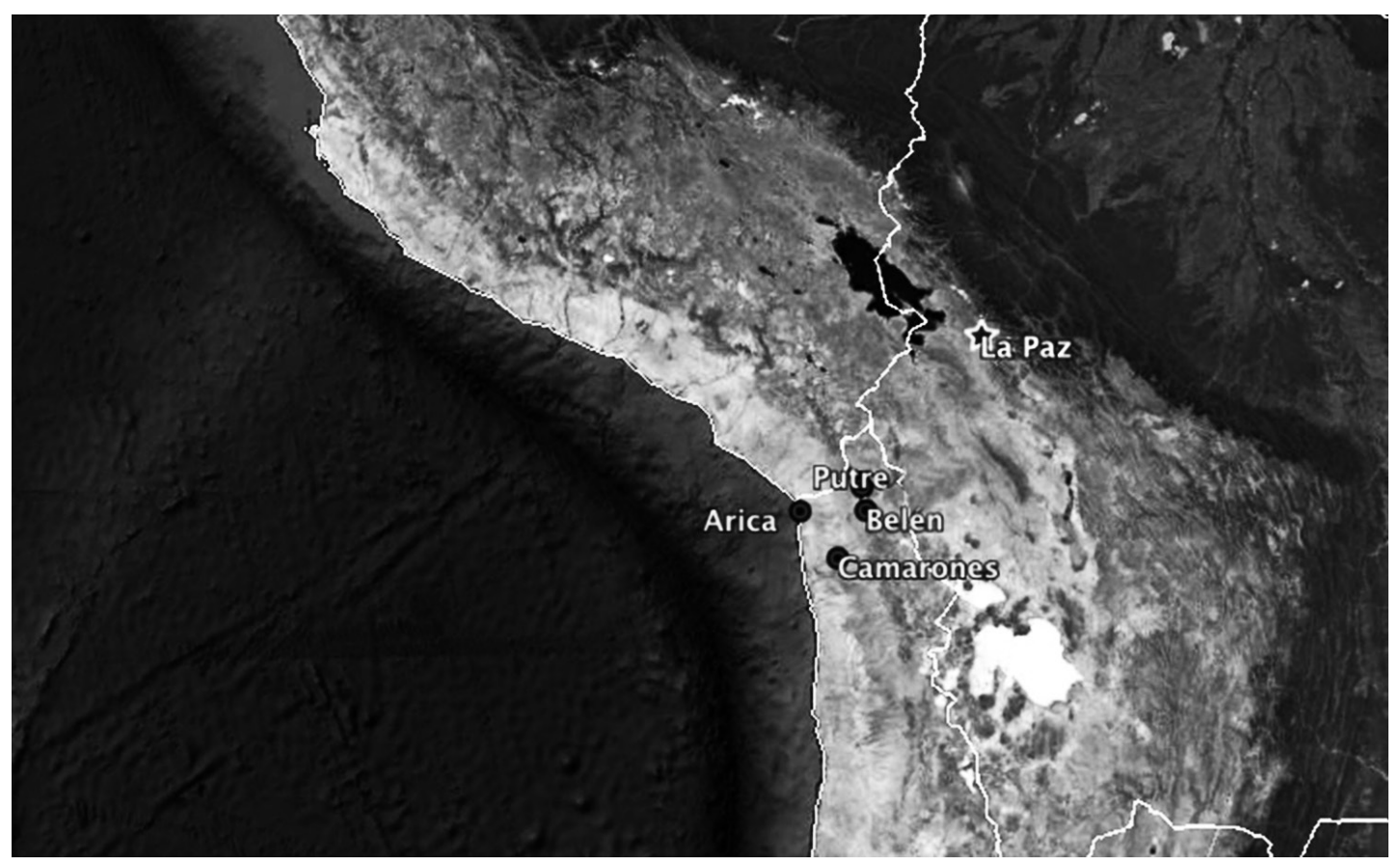

Figura 1. Mapa de la zona de estudio y principales ciudades de la región de Arica y Parinacota (Arica, Camarones, Putre y Belén). Map of the study zone and principal cities of Arica and Parinacota Region (Arica, Camarones, Putre and Belén).
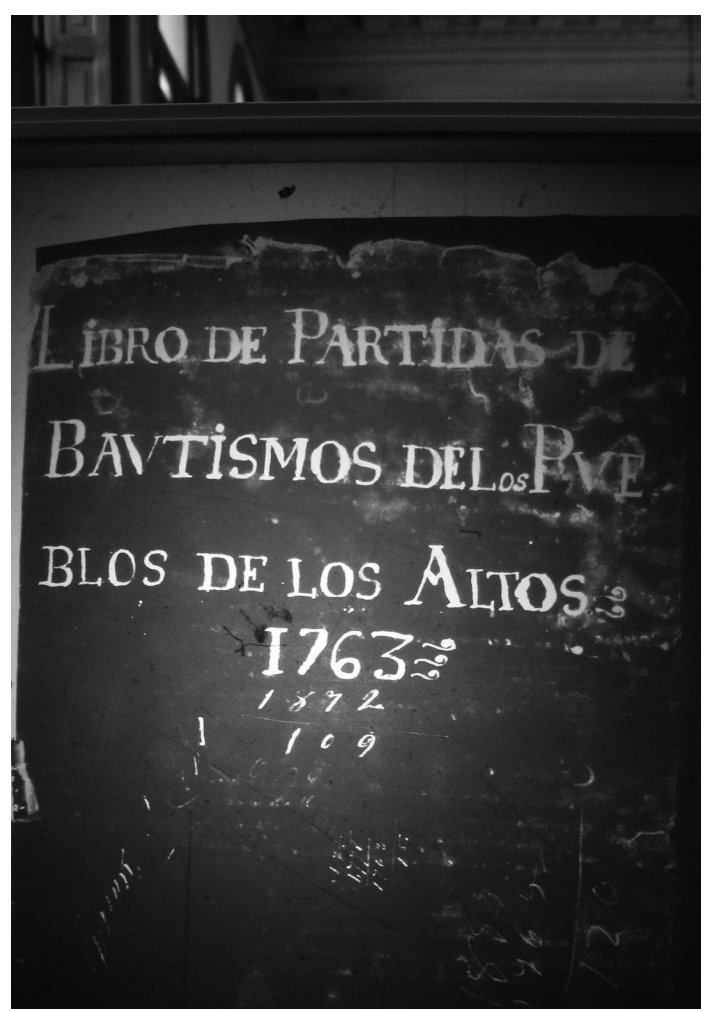

Figura 2. Portada del libro de bautizos de la parroquia de Belén (1763).
1979, Marramao 2013, Quijano 1992); pese a ello, aún falta mayor vocación de diálogo y más autocrítica desde las disciplinas sociales. No solo porque los colectivos que estudia la historia y la antropología son partes constituyentes de las fuentes y los conceptos elaborados, sino porque también le brindan a la investigación científica una necesaria ventilación teórica gracias al trabajo de campo; sobre todo en los contextos neocoloniales o de colonialismo interno que actualmente se desdibujan en los Estados-nación respecto de los pueblos originarios (Chatterjee 2008, Comaroff y Comaroff 2011, Viveiros de Castro 2010). Por ende, debemos ocuparnos sobre los aspectos materiales y simbólicos de nuestros enunciados, así como ser más cautelosos sobre los efectos políticos de nuestra práctica (Boccara 2013, Salomon 2013). Incluso más, este vínculo dialogante se vuelve forzoso si queremos realmente hacernos cargo de la heterogeneidad de reacciones que provocan nuestros estudios en el mundo indígena, evitando con igual énfasis tanto los odiosos paternalismos como la infantilización de nuestros interlocutores (Albó 2007, Antileo 2013, Ayala 2008, Nahuelpán 2013, Rivera Cusicanqui 2010, Salomon 2001, Uribe y Adán 2003). 


\section{Apuntes Metodológicos}

En nuestro caso, previo a la visita de terreno en Belén, fue necesario aunar criterios y procedimientos entre ambas disciplinas, la historia y la antropología, para generar un espacio de intercambio y construcción de conocimiento que estableciera relaciones recíprocas entre la comunidad local y las investigaciones universitarias. Es decir, en primera instancia propiciar un diálogo interdisciplinario para abordar las demandas de divulgación de los estudios académicos hacia los colectivos que aluden, cuyo ejercicio nos acompañó a lo largo de todo el proyecto en nuestro intento por consensuar las diferentes perspectivas y los conceptos suscitados a partir de cada disciplina. En paralelo a esta etapa inicial se visitaron las dependencias del Archivo Nacional en Santiago donde se encuentran los Libros de la Parroquia de Belén; el objetivo de esta actividad fue filmar una pieza documental que diera cuenta del contexto y las condiciones en que se hallan tales registros, permitiéndonos así visibilizar un objeto para facilitar el debate entre la comunidad y los investigadores.

El trabajo de campo consistió principalmente en un taller con la junta de vecinos del pueblo de Belén durante abril del año 2013 (Figura 3); allí participaron diferentes miembros de la comunidad local, tanto quienes residen en el entorno así como aquellos que viven en la ciudad de Arica, pero que mantienen vínculos permanentes y de diversa índole con este lugar. En el taller se mostró la pieza documental y se expusieron los resultados más relevantes de la investigación en curso (Figura 4); posteriormente se abrió la conversación hacia la comunidad, lo que generó un fructífero diálogo entre los propios beleneños así como también entre ellos y los investigadores presentes. Una segunda actividad se desarrolló un mes después en colaboración con el proyecto " 170 Escuelas - 170 Académicos y Académicas"3, donde visitamos el

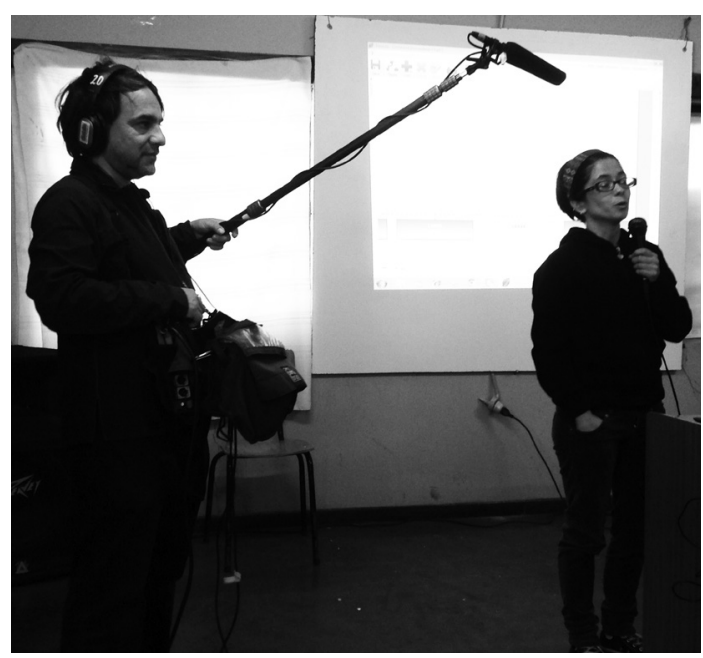

Figura 4. Xochilt Inostroza, académica exponiendo a la Comunidad mientras se realiza el registro audiovisual del taller.

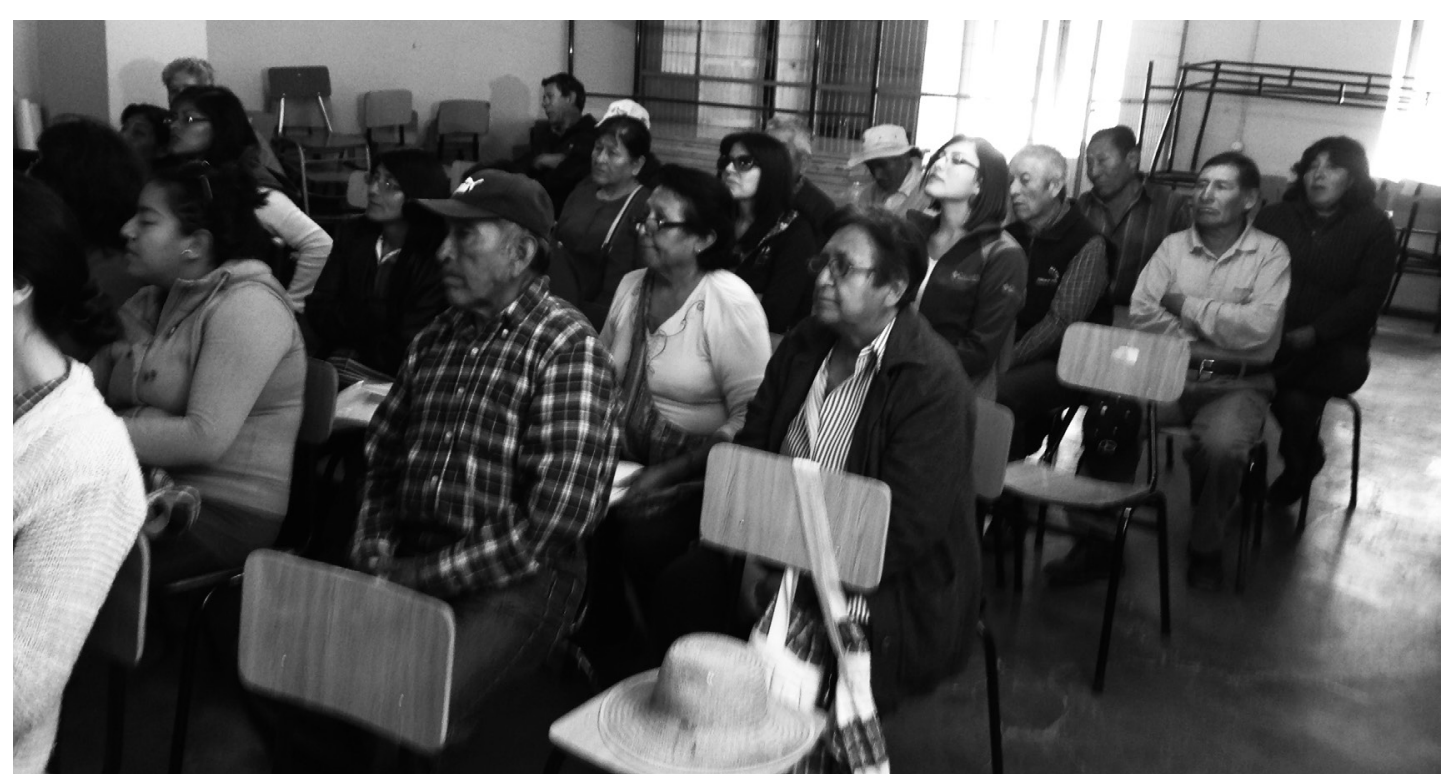

Figura 3. Taller con la Comunidad de Belén. 
Liceo de Putre y la Escuela Básica de Belén para presentar algunos aspectos de la investigación mencionada, adaptando su contenido a las edades de los estudiantes e intentando motivar otros diálogos en torno al tema.

Asimismo, el encuentro entre la comunidad local y las disciplinas académicas provocado en el marco del primer taller en Belén, fue igualmente registrado en una segunda pieza documental ${ }^{4}$ que recogió en extenso las distintas intervenciones efectuadas por los participantes. Se trata de un testimonio que plasma los resultados de dicha conversación; donde se intentó reflejar la enorme relevancia concedida a los registros parroquiales por los beleneños y la academia, sus diferencias y similitudes, así como también las diversas perspectivas enarboladas en torno a las identidades culturales y la heterogeneidad de discursos que se fueron orquestando en la memoria local y andina.

Puesto que el proyecto fue ejecutado desde la universidad y debido a lo acotado de sus tiempos, las reacciones y los debates suscitados al interior de la comunidad beleneña solo pudieron ser abordados a manera de indicios en este trabajo de campo. Aunque se pretende darle continuidad a la relación iniciada entre investigaciones académicas y la comunidad local, nuestras observaciones en terreno carecen de la densidad y la profundidad propias de una experiencia etnográfica prolongada que permita dar cuenta de la complejidad interna y las diferentes posiciones que entraman el tejido social de Belén. En efecto, estamos conscientes de que este tipo de reflexiones se sostienen en un proceso dinámico en permanente construcción, no solo entre las disciplinas académicas y las comunidades locales, sino también al interior de cada una de ellas y a largo plazo.

Sin embargo, pensamos que este primer acercamiento a la dimensión objetual y patrimonial de los archivos (p. ej., históricos) nos otorga una pincelada sugerente sobre los distintos puntos de vista expuestos durante el taller, a la par que constituye un valioso ejercicio de diálogo interdisciplinario que igualmente precisa de ir enriqueciéndose y haciéndose más denso. De este modo, desde el ámbito académico se vuelve forzoso no solo generar espacios de discusión entre las diferentes disciplinas, sino que además establecer pautas de difusión y reflexión para las investigaciones universitarias en correspondencia con una voluntad dialogante hacia las comunidades locales o grupos interpelados.

\section{Y Algunas Consideraciones Teóricas}

Es así que esta experiencia nos situó en un escenario idóneo para contextualizar cómo los discursos emanados desde la universidad, que inevitablemente forman parte de las narraciones del Estado-nación y del modo de producción capitalista, también son apropiados por sujetos andinos para construir sus propios relatos históricos que, paralelamente, van retroalimentando a las historias hegemónicas (p. ej., Antileo 2013, Choque 2012, Mamani 2007, Nahuelpán 2013, Rivera Cusicanqui 2010, Uribe y Adán 2003). En este sentido, el poder no es una sustancia o una cosa que se distribuye de manera diferencial entre personas y grupos diversos conforme a un tiempo histórico lineal donde se van sucediendo las distintas formas de organización política; por el contrario, posee un carácter eminentemente relacional y generativo, caracterizado tanto por flujos como por cortocircuitos donde intervienen la violencia y el juego azaroso de las dominaciones (Marramao 2013: 84-85). Es justamente este régimen situacional y político en torno a las prácticas de la memoria lo que constituye un andamiaje a partir del cual los actos de recuerdo y olvido son siempre selectivos, productores de silencios y permeados por las condiciones coloniales en que emergen (Boccara 2013, Connerton 1989, Salomon 2001). Sin embargo, las historias que implícita o explícitamente celebran el advenimiento del Estado y la idea de la ciudadanía, omiten o desestiman la importancia de la represión y la violencia que identifican tanto a la victoria de lo moderno como al poder de convencimiento de los discursos hegemónicos (Foucault 1979).

En efecto, la noción de "colonialismo internalizado" (Fanon 2003 [1973]) sugiere que la puesta en marcha de un sistemático proceso de despojo y subsunción, tanto de territorios como de cuerpos por medio la violencia y la disciplina tutelares, ha permeado el campo de la subjetividad de los propios pueblos colonizados junto al despliegue de sus contradictorias y heterogéneas identidades. Por eso se puede decir que, parafraseando, los condenados de la tierra son también "condenados de la memoria"; pues existe a la vez un doble secuestro y silenciamiento de experiencias y voces mediante la imposición de un ejercicio análogo acerca de lo que puede o no ser concebido como histórico. Es que en el afán por construir una "contra-historia" que remarque 
los derechos colectivos y nutra las demandas de autonomía de los pueblos originarios, se corre el riesgo de reforzar o crear nuevas subalternidades al ignorar ciertos procesos e identidades que no encajan con la representación del pasado y presente que se desea construir y movilizar (Nahuelpán 2013: 25).

Por eso no solo se requiere hacer deliberadamente visibles las estrategias y las prácticas de disciplinamiento propias de los discursos científicos, por ejemplo, el papel que tiene en colusión con las narraciones de ciudadanías al asimilarse a los proyectos del Estado moderno por encima de todas las demás posibilidades de colectividad social; sino que además en dicho propósito se debe evitar un relato homogéneo, universalizante y hegemónico en virtud de su constante reelaboración conforme los vínculos de poderes pasados, presentes y contingentes. A nuestro juicio, esto es plausible realizarlo sobre todo mediante el trabajo de campo donde las ideas científicas se enfrentan con otras pragmáticas intelectuales, lo que permite complejizar la "dialéctica entre hegemonía y contrahegemonía" (Comaroff y Comaroff 2011: 218). De tal modo que se van conformando imaginarios cada vez más incómodos y polimorfos que convocan a la comprensión de un mundo social siempre cambiante, heterogéneo y vivo.

\section{La Experiencia en Belén}

El encuentro con la comunidad de Belén se realizó el día 20 de abril del año 2013, donde participaron 33 comuneros correspondientes a las familias de apellidos Alanoca, Andia, Apas, Arias, Colque, Cruz, Guillén, Huarache, Mamani, Santos y Zegarra. Desde el lado de la academia estuvieron presentes cuatro académicos tanto de la Universidad de Chile como de la Universidad de Tarapacá y un historiador aymara oriundo del pueblo de Socoroma; igualmente se contó con el apoyo de dos expertos para el registro audiovisual de esta instancia. También asistieron al taller una concejala de la comuna de Putre, quien actuó como comunera a la vez que representante del gobierno local que actualmente aglutina a estos pueblos, junto a dos integrantes de la Fundación Altiplano cuya institución estuvo a cargo de la reciente reconstrucción de la Iglesia Virgen Candelaria en Belén.

La mayoría de los comuneros llegaron temprano en la mañana gracias a un bus dispuesto por la Municipalidad de Putre. Es que los miembros de la comunidad se hallan dispersos, algunos residen en el pueblo y sus alrededores (Figura 5), mientras que la mayoría vive en Arica y mantienen mecanismos de residencia múltiple junto a los

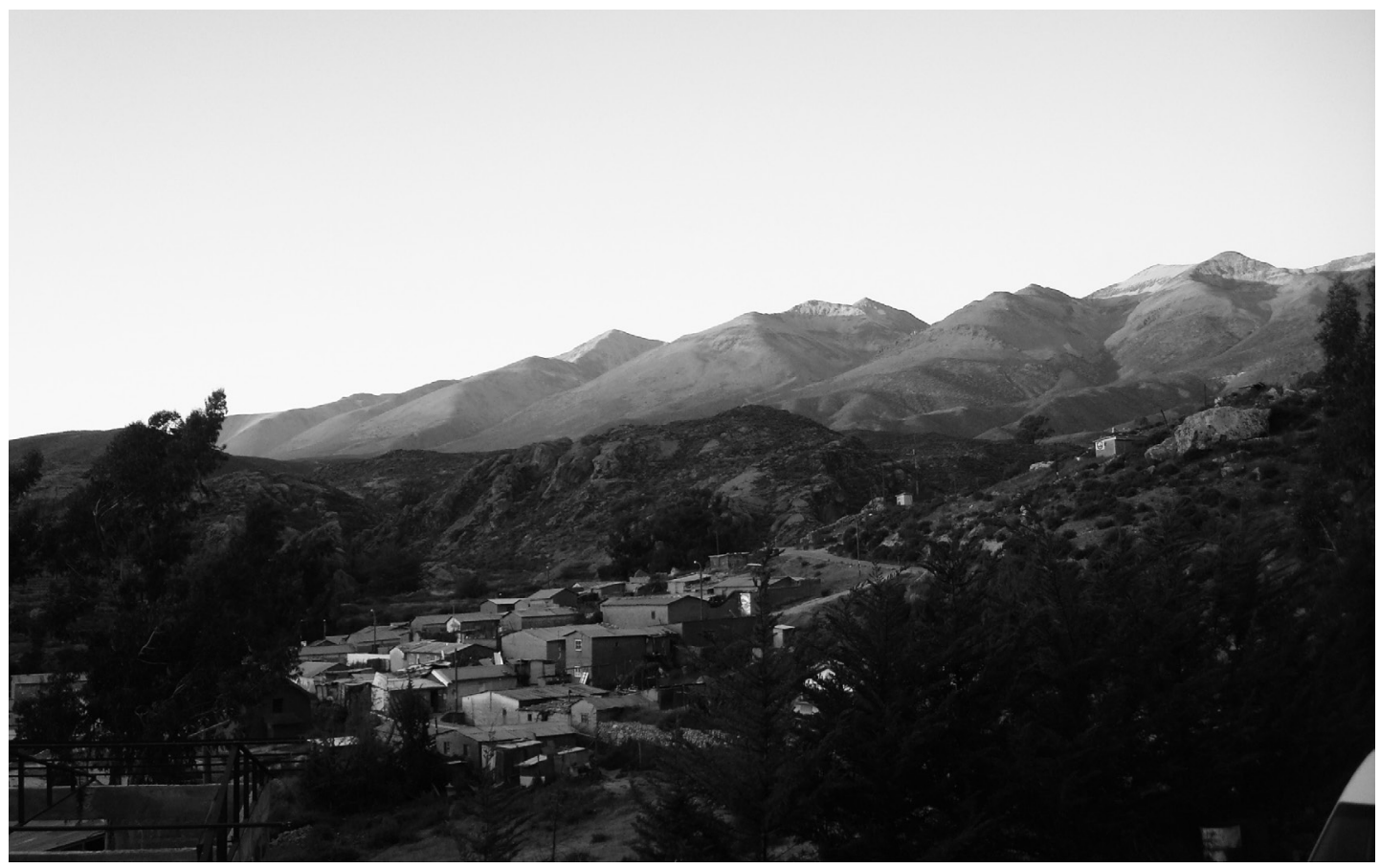

Figura 5. Pueblo de Belén. 
complejos arreglos de trabajo y los subsecuentes compromisos de reciprocidad entablados a lo largo del ciclo productivo, social y ceremonial comitario. En efecto, para hacer usufructo de los recursos comunales, primero se debe "ser mayordomo en alguna de las festividades religiosas del pueblo" (Eddie Zegarra Santos, Pdte. Junta de Vecinos y Comunidad Aymara de Belén) ${ }^{5}$. En Belén, el sistema de cargos está organizado según mayordomos mayores y mayordomos menores. Los primeros están encargados de pasar las fiestas más importantes como San Santiago, Virgen Candelaria y Crucificado en Semana Santa; los segundos corresponden a las celebraciones de Santa Bárbara, Carnavales y Virgen del Rosario (María Nila Santos Cruz, mayordomo principal de turno, Figura 6). Asimismo, la gente de Belén se divide entre "alteños" y "abajeños" cada uno con su iglesia, Virgen Candelaria y San Santiago, respectivamente (Figuras 7 y 8). Es que el cumplimiento de cargos también forma parte de los "senderos de la memoria" o amt'añ thaki

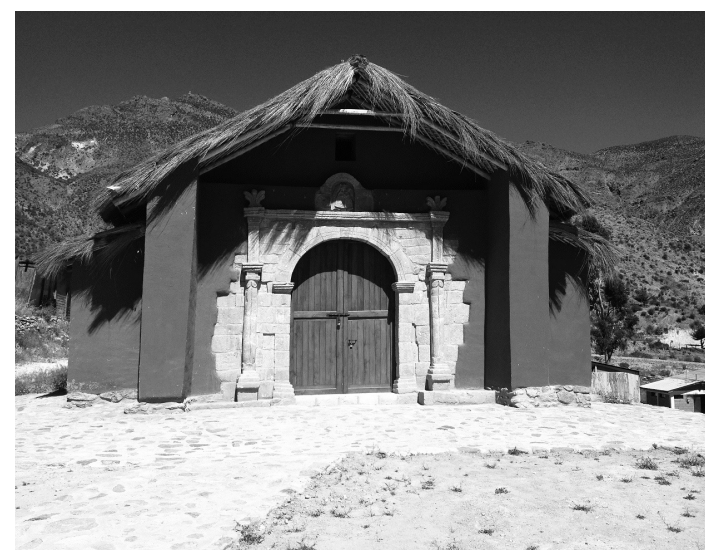

Figura 7. Iglesia de San Santiago.

practicados por las comunidades andinas tanto en Bolivia como en Chile (Abercrombie 2006 [1998], Albó 2007, Choque 2012). Cabe destacar, entonces, que el thaki comunal va germinando mediante el establecimiento de diversas trabazones

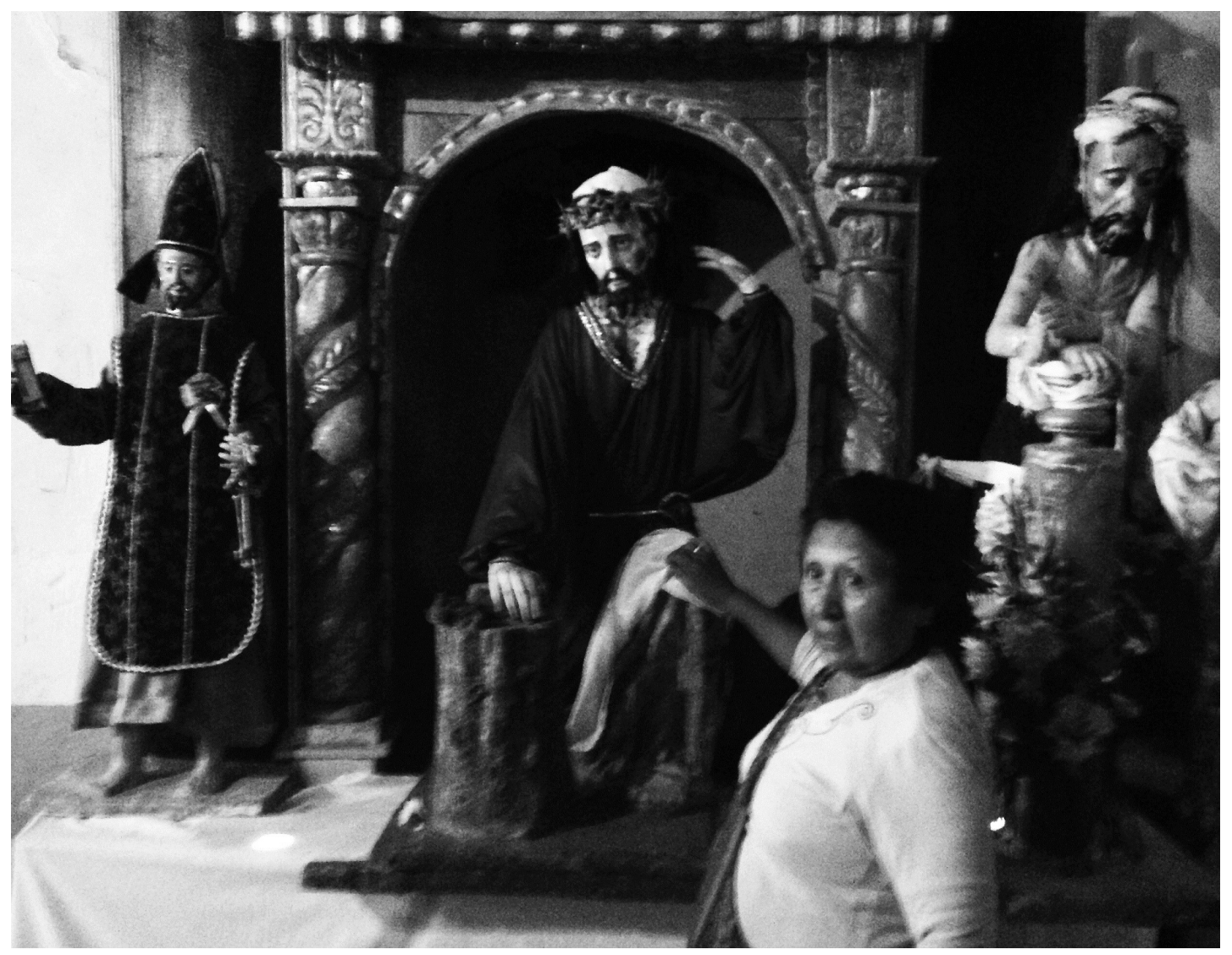

Figura 6. María Nila Santos Cruz, mayordomo principal de turno de la Iglesia San Santiago. 


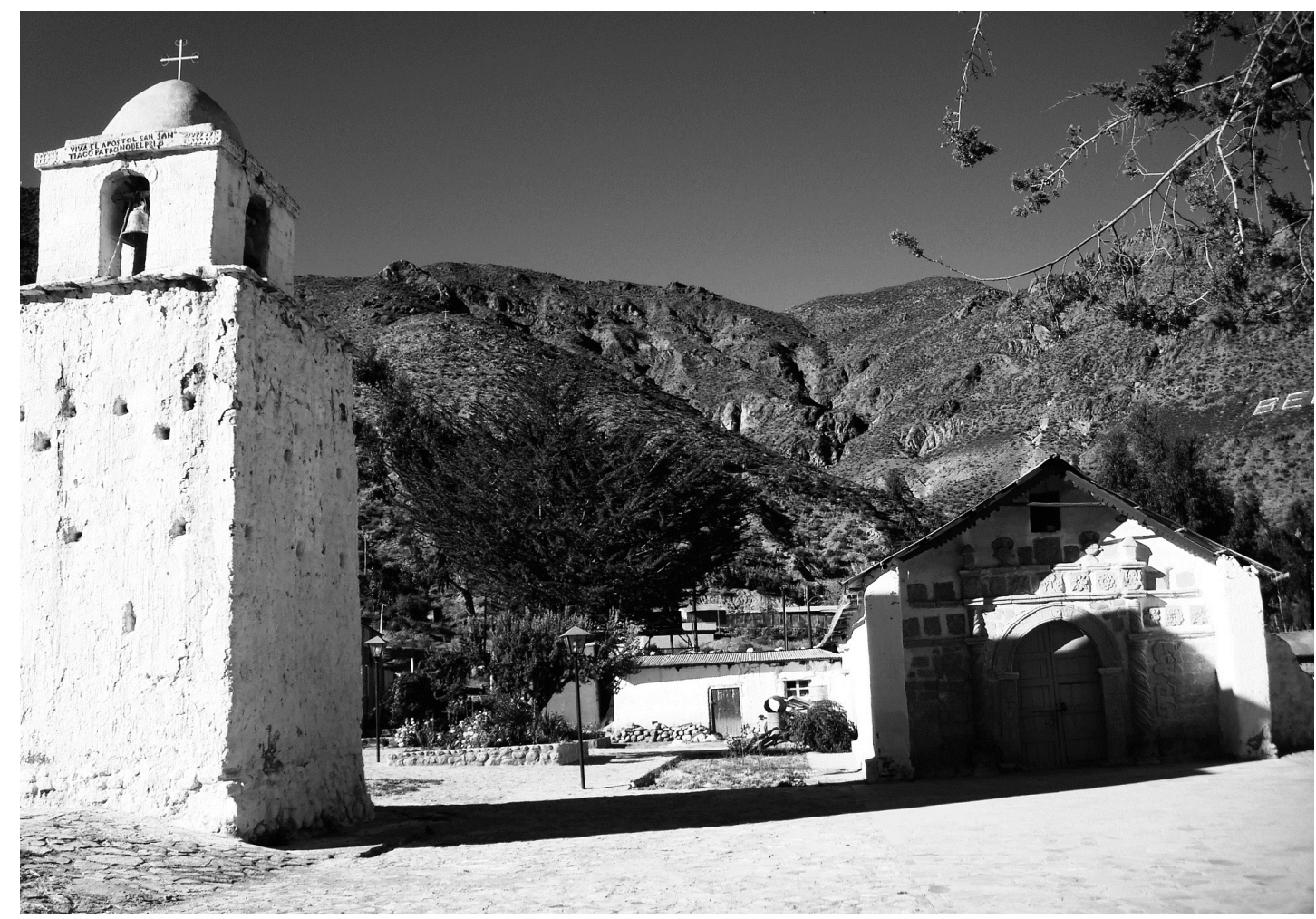

Figura 8. Iglesia de la Virgen de la Candelaria.

recíprocas o ayni respecto de los pasantes de dichas festividades.

Por otro lado, la importancia que tuvo Belén como capital de la antigua Doctrina de Belén constituye una memoria que se resiste a desaparecer, la cual fue enarbolada en la lucha que dieron sus dirigentes para evitar ser cooptados bajo la administración de Putre y así mantener la actual Oficina del Registro Civil con sede en su pueblo. Aquí se lleva a cabo la realización de los registros de nacimiento, matrimonio y defunción de las personas de Belén y las localidades vecinas, teniendo entre sus archivos inscripciones que se inician desde fines del siglo XIX hasta nuestros días y que le brindan continuidad a los registros parroquiales coloniales tratados en este caso, pues ambos conservan los mismos protocolos escriturales. Coincidente o no, por lo tanto, la función que cumplían los curas párrocos de la jurisdicción de Belén en la época colonial hoy está presente en una nueva institucionalidad y bajo la responsabilidad de autoridades locales, manteniendo esa identidad de "centro administrativo" de la que otrora fuera la Doctrina. Esta versatilidad y complejidad de los procesos de memoria se ve plasmada con elocuencia en la figura del encargado del registro civil (Eddie Zegarra Santos); quien además de presidente de la Junta de Vecinos y de la Comunidad Indígena de Belén, resulta ser el consejero aymara por la comuna de Putre y custodio de la "vara" o el bastón de mando, cuya posesión marca el pináculo del sistema de cargos en las sociedades andinas contemporáneas (Figura 9).

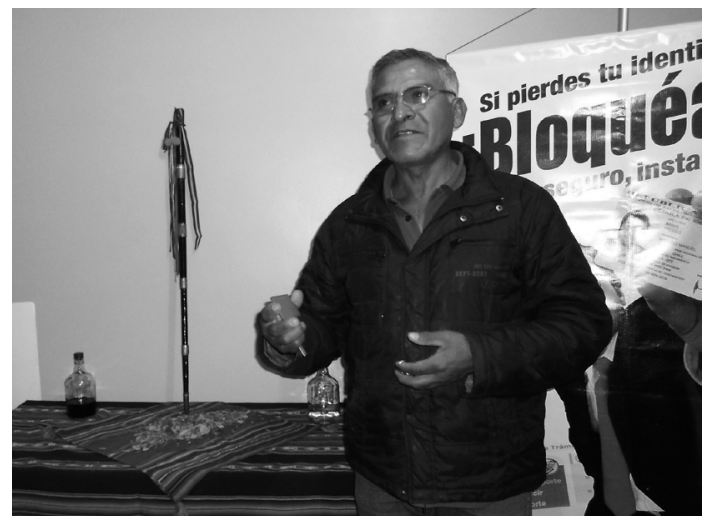

Figura 9. Eddie Zegarra Santos, presidente de la comunidad y funcionario de la oficina del Registro Civil de Belén junto a la "vara" del pueblo. 
Fueron algunos de estos temas, antes de dar inicio al taller, los que se conversaban coloquialmente entre comuneros y demás visitantes alrededor de la plaza del pueblo, ubicada entre la Iglesia de San Santiago y las dependencias municipales; mientras en la sede vecinal, ubicada a un costado del municipio, se realizaban los preparativos para la presentación del estudio sobre los libros parroquiales y se alistaban los equipos para el registro audiovisual. Poco a poco los asistentes fueron llegando al salón y tomaban asiento en las sillas que habían sido dispuestas frente a un telón. Cuando todos estuvieron reunidos, el presidente de la Junta de Vecinos y de la Comunidad Indígena se dirigió para darles la bienvenida a los investigadores, les agradeció el interés por difundir su trabajo en el pueblo y le cedió la palabra al historiador socoromeño. Este, en su posición bisagra de aymara y académico, saludó a los participantes en nombre de los investigadores allí congregados y les pidió permiso para filmar el encuentro.

La primera actividad consistió en exhibir la pieza documental filmada previamente. Allí se mostraron los libros parroquiales, sus añosas páginas y su elaborada caligrafía; también se apreciaba el monumental edificio donde estaban alojados y toda la parafernalia implicada en su manipulación. El acceso a los documentos originales solo puede efectuarse visitando el Archivo Nacional en Santiago, donde existen funcionarios encargados de controlar las visitas; la revisión de su contenido opera principalmente por medio de formatos digitales que facilitan la investigación científica debido a las restricciones del contacto directo con estos objetos, pues para tocarlos se requiere el uso de protocolos (p.ej., guantes). Algunos beleneños sabían de la existencia de los registros parroquiales, pero pensaban que tales papeles posiblemente se habrían perdido en los fragores de la Guerra del Pacífico y la posterior "Chilenización"; o bien, pudieron haberse quemado en los rituales funerarios de caciques o mayordomos. Es así que la presencia de estos documentos en el Archivo Nacional de Santiago era hasta entonces desconocida por los comuneros.

Al finalizar la exhibición y ver ahí los apellidos suscritos, tales registros fueron considerados de significativo valor para reafirmar la profundidad temporal en que se enmarca la presencia de la comunidad dentro de este territorio; sobre todo para demandar un reconocimiento constitucional como pueblo originario y poder vincularse con los organismos estatales y sus políticas públicas, permitiendo contar con una herramienta jurídica más que los habilite para enfrentar colectivamente a las empresas mineras que están instalándose en los alrededores. Asimismo, los reclamos o los comentarios acerca de un posible retorno de los registros parroquiales a la comunidad de Belén, estuvieron prácticamente ausentes; salvo por la intervención del anfitrión del pueblo, Eddie Zegarra Santos ${ }^{6}$, quien apuntó sobre las condiciones de seguridad y conservación de los libros en el Archivo Nacional, posibles de apreciar en el documental exhibido durante el taller. "Si bien no preguntaron el porqué no volvían los documentos a su lugar de origen, se vieron más interesados en el contenido de información de tales documentos; es decir, se preocuparon más en ver los resultados de investigación y reconstrucción familiar" (Cristián Arias Huarache, beleneño y estudiante de Historia en la Universidad de Tarapacá).

En este contexto, la investigadora principal expuso a la comunidad los estudios etnohistóricos realizados a partir de los libros parroquiales. Cabe recordar que este tipo de registros fue implementado por la Iglesia Católica durante el siglo XVIII y sancionaba los principales eventos de la sociedad indígena (nacimiento, filiación, alianza y muerte), permitiéndole al sacerdote adoctrinar en los sacramentos del bautismo, el matrimonio y la defunción a la población de su parroquia, para así cristianizar y controlar la idolatría de manera más eficiente. Específicamente, los libros de Belén tienen la riqueza de inscribir a la gran mayoría de las personas con sus nombres y apellidos desde el año 1763 hasta 1859; esta característica, sumada a su óptimo estado de conservación, ha permitido aplicar el método de "reconstitución de familias", con el que se analizan cifras sobre ciclos vitales y elementos demográficos, a la par que permite examinar la distribución cuantitativa de aspectos socioculturales relativos a la familia y la comunidad (Inostroza et al. 2014). Entonces, la intención manifestada por los historiadores de hacer público este conocimiento fue para enriquecer la memoria social y la identidad cultural de los beleneños, de tal modo que la comunidad se apropiara de su contenido y pudiera utilizarlo en su experiencia presente.

Al escuchar los apellidos que aparecían en los registros parroquiales, los comuneros fueron distinguiendo con rapidez su vínculo con determinados pueblos o sectores que antiguamente formaban parte de la Doctrina de Belén. Fue sugerente presenciar 
la avidez con que preguntaban si su apellido aparecía allí; también se inquiría a los investigadores sobre el origen de las familias, las vinculaciones entre comunidades y territorios, etc. El ritmo de la conversación denotó motivación e interés de ambas partes por hacer interlocutar las diferentes formas de conocimiento, quedando en evidencia cómo los beleneños han integrado en la rememoración de su pasado algunos aspectos que la historia, la antropología o la arqueología consignaron en sus estudios $^{7}$. La escuela y la universidad son las sedes institucionales donde se produce el conocimiento, pero también existe un proceso de apropiación de dicho discurso en beneficio de la construcción de una identidad comunitaria. Porque no es la cultura andina, sino las mujeres y los hombres andinos de determinadas épocas quienes han resistido las fuerzas de la dominación, apoyándose en una memoria social de elaboración colectiva para aprehender las hegemonías a las que están sujetos con el fin de volverlas a desplegar creativamente en forma de contrahegemonías; sean estas forjadas desde la tradición como imbricadas en modelos de etnicidad y mercado (Comaroff y Comaroff 2011), donde se ponen en escena los juegos de poder y las posiciones de autoridad (Foucault 1979, Quijano 1992, Uribe y Adán 2003).

"Nosotros no sabíamos nada, ahora ya sabemos que los libros parroquiales están en Santiago [...] Sería bueno dejarnos a nosotros una hojita, para saber y dejar a nuestros hijos, para que sigan haciendo nuestras fiestas, para que vuelvan y se sigan nuestras costumbres" (Natalia Santos Colque). "Belén siempre ha sido un centro donde sus autoridades supieron negociar, en cambio los otros pueblos se enfrentaron y salieron perdiendo [...] Las familias más numerosas eran las principales, por eso había importancia de tener hijos y de tener compadres. Hasta el 65 este pueblo era vivo, se iba en caravanas a otros pueblos para intercambiar en las fiestas, viajar era costumbre de tener padrinos, ahijados y compadres [...] Yo insto a los profesores a seguir investigando para que la gente vuelva a estos pueblos" (Abdón Apas Santos). "Yo tengo orgullo de ser beleneño, no por lo que dicen, sino por la historia" (Edgard Guillén Santos). "El ciudadano refuerza el saber de la academia y la academia refuerza el saber del ciudadano, hay un enriquecimiento mutuo entre las investigaciones universitarias y las memorias locales" (Nelly Alanoca Santos).
Los libros, somos majaderos, fueron unánimemente valorados como "un valioso instrumento para saber sobre nuestros antepasados" (Eddie Zegarra Santos). Se trata de archivos "que estaban durmiendo"; conocer su existencia significaba "comprobar nuestra identidad quechua-aymara, que somos los hijos del sol y los habitantes ancestrales del continente Abya Yala" (Bárbara Mamani Yucra). Este tipo de discursos supone la investidura de categorías modernas que desde el Estado o la academia pueden parecer antojadizas e incluso imposibles; pero que nacen de un contrapunto entre la constitución de la identidad como persona jurídica e ideal por un lado, y la transformación capitalista de la cultura en mercancía por el otro (Comaroff y Comaroff 2011) ${ }^{8}$. Esta evocación representa un proceso abierto a la intervención de los regímenes, las instituciones y las prácticas occidentales y del mercado; pero que a la vez está mediado por la pragmática de la existencia cotidiana, las reivindicaciones de la diversidad cultural y las luchas por el reconocimiento constitucional. Por lo mismo, puede encender el motor de la dominación o prender la chispa de la rebeldía, lo cual supone diferencias y tensiones sociales al interior de las comunidades entre aquellas posiciones que denotan una "etnicidad discursiva" vinculada con los relatos hegemónicos y aquellas perspectivas sobre una tradición que se vive de manera cotidiana así como contradictoria (Albó 2007); donde, finalmente, también se despliegan diversas "identidades situacionales" conforme van cambiando los interlocutores y las respectivas relaciones de poder que los imbrican (Nahuelpán 2013, Salomon 2001, Urrutia 2011).

Así, en el espacio de enunciación local se desprenden percepciones pormenorizadas y posiciones intermedias que aúnan repertorios aparejados a la vez que dispares en relación con los discursos hegemónicos de la universidad y el Estado-nación. A partir de su propia heterogeneidad, el discurso desde la comunidad ("interés", "orgullo", "volver a los pueblos", "se sigan nuestras costumbres", "saber sobre nuestros antepasados", "comprobar nuestra identidad", "somos los hijos del Sol y los habitantes ancestrales", "enriquecimiento mutuo") permite palpar una suerte de conversación silenciada a lo largo del texto académico (Salomon 2013); expresando mediante dimensiones materiales y simbólicas la condición subalterna de sus enunciados, al mismo tiempo que reivindican activamente sus propias representaciones históricas. 


\section{En Torno a las Investigaciones Académicas y su Presentación a la Comunidad Local}

Desde los primeros tiempos de la conquista las sociedades indígenas se han enfrentado al arte y la política de la escritura moderna en tanto forma privilegiada para comprender y transmitir el conocimiento, siendo escuelas y universidades las sedes institucionalizadas para la producción y divulgación de los distintos ámbitos del saber académico. En el contexto regional de Arica existe una rica tradición entre académicos e investigadores locales para articular dinámicamente la información tanto histórica como antropológica con los intereses y las demandas de las colectividades andinas (p.ej., Choque 2012, Galdames y Díaz 2007, Moraga et al. 2010, Ruz et al. 2008). Es así que desde el campo académico de Arica se han estudiado numerosos registros y se han realizado múltiples investigaciones que sintonizan con temas afines a la realidad de las comunidades indígenas; propiciando un intercambio de conocimientos enmarcado en la traducción cultural de fuentes y escritos hacia los múltiples soportes y prácticas andinas; a la par que plasmando cómo las distintas modalidades de apropiación del espacio y sus correspondientes colectividades están relacionadas con los contextos históricos que han debido enfrentar (p.ej., Carrasco et al. 1992, Díaz et al. 2010, Gavilán 2013, González et al. 2014, Ruz et al. 2008). Explícita o implícitamente, el quehacer antropológico e historiográfico se siente interpelado por el acucioso afán de las comunidades en recordar y hacer frente a sus pasados, más que en heredar pasivamente cierta historicidad (Moraga et al. 2010); al respecto, su divulgación no solo opera en espacios formales sino que también se procura dentro de las propias comunidades y las instituciones gubernamentales.

En directa relación con lo anterior, el fenómeno de la "Chilenización" tras la Guerra del Pacífico ha recibido una atención especial y es abordado como un proceso social dinámico, donde los conceptos de aculturación y de artefacto cultural permiten visualizar una amplia gama de matices y flujos entre identidades tradicionales y ciudadanías nacionales, que en la práctica no solo coexisten y se entremezclan sino que se refuerzan recíprocamente a través de un acomodo y un ajuste entre las diferentes sociedades implicadas en el conflicto fronterizo (Galdames y Díaz 2007: 25). Por su parte, los intelectuales indígenas también han escudriñado este fenómeno desde la memoria andina para apuntar cómo esta nueva imposición fue articulada con antiguas divisiones internas y cómo los actos de olvido forzado supusieron la reconfiguración de las identidades locales interpretadas en clave ciudadana (Choque 2010). Acorde a esa perspectiva, lo andino tiende a entenderse cada vez más a partir de "modos de habitar" que bajo imposiciones del orden colonial primero y republicano después van desplegando nuevas formas en las que el pasado se hace presente, aunque de manera subalterna (Gavilán 2013: 459).

Bajo este marco se produce el diálogo y la convivencia entre academia y comunidades indígenas dentro de Arica. Sin embargo, no resulta novedoso señalar que tanto aquí como en otros lugares, el colonialismo, el desequilibrio de fuerzas y el racismo se siguen manifestando bajo otras formas; o que desde su condición subalterna los agentes y los estudiosos "indígenas" hacen nuevas preguntas al pasado y cuestionan sus usos, derribando de paso el mito sobre un conocimiento fijo (Boccara 2013). $\mathrm{Si}$ inquirimos a las culturas andinas en relación con un territorio determinado y su relacionalidad en un contexto históricamente situado, también nos toca inquirir sobre nuestras prácticas académicas y nuestros significados teóricos acorde con los cambios históricos que se están dando en nuestras sociedades dominantes. La difusión del conocimiento histórico y antropológico se desenvuelve de manera primera e inevitable desde lugares de enunciación hegemónicos; principalmente a partir de la publicación en revistas especializadas, actividades de formación e investigación, así como crecientemente por medio del diseño, la ejecución y la evaluación de una serie de proyectos emanados desde las instituciones gubernamentales, las agencias multilaterales y cada vez más desde las empresas privadas.

Por lo mismo corresponde reiterar que la memoria social no solo se construye y se sostiene a partir de narrativas insertas en relaciones de poder contingentes, más bien hace del pasado una fuerza presente al entrelazar el lenguaje y su retórica social con la materialidad y las prácticas corporales; pues la memoria colectiva se fija principalmente por medio de actos performativos donde ciertos artefactos y rasgos son dotados de agencia (Connerton 1989). Los libros de Belén, en tanto referentes materiales de una memoria corporalizada, fueron administrados por la Iglesia Católica y actualmente forman parte de un patrimonio nacional que requiere ser conservado, cuyos discursos hegemónicos operan normalizando y categorizando archivos en sus 
diferentes soportes. En este sentido, la materialidad de los libros resulta ajena para los beleneños, lo mismo que su interpretación científica por medio de métodos históricos y demográficos. De este modo, nuestra performance desplegada también contribuye a este distanciamiento en la medida que inconscientemente nos situamos desde una posición generadora de conocimientos frente a una comunidad que aprende y hace preguntas; muy en sintonía con la lógica académica y el comportamiento en las aulas de la universidad, representando el permanente e inconsciente equívoco de la relación entre academia y comunidad. En efecto, durante el taller, los investigadores nos paramos frente a los comuneros; no solo de manera física al exponer los resultados de las investigaciones delante de la comunidad, sino también en términos discursivos al enarbolar el origen científico que amparaba a los datos y fechas consignados por los comuneros en algunos de sus relatos históricos.

No obstante, si los investigadores buscamos establecer un intercambio horizontal entre diferentes formas de conocimiento, debemos cuestionar tanto las dimensiones narrativas como las prácticas del cuerpo sobre las que se sostiene un determinado registro sobre el pasado. El modo en que se desarrollan los actos conmemorativos así como el tipo de comportamientos inscritos en ciertos rasgos y movimientos corporales, aquello que no se dice pero se actúa, también informan sobre el patrón de memoria social en un contexto histórico y político dado (Connerton 1989). A diferencia de esto, se requiere una reflexión crítica y un cambio de actitud que revierta esa lógica conservadora del acto académico, que sitúa el diálogo con la comunidad a partir de "prácticas de devolución" donde nosotros exponemos y ellos recepcionan.

"El trabajo del historiador, así como también el oficio del sociólogo o del antropólogo, consiste en tratar de asir las dinámicas sociales en sus aspectos tanto representacionales como materiales, pues, a fin de cuentas, son inseparables. Se trata de dar cuenta de las articulaciones entre los mecanismos de poder y las dinámicas socioculturales o de las relaciones entre cultura y poder en un espacio social dado" (Boccara 2013: 526).

Estos actos, por lo tanto, nos convocan a la autocrítica. Al respecto, Boccara (2013) establece con lucidez las paradojas y las relacionalidades que ensamblan a nuestra época, al ironizar sobre el desencuentro entre las múltiples estrategias desplegadas por las poblaciones originarias para existir en tanto pueblos dotados de unos derechos y de una etnicidad claramente definidos con el fin de sustraerse al colonialismo y al racismo que se siguen perpetuando bajo nuevas formas; lo cual desentona con las preocupaciones de antropólogos e historiadores. Estos últimos, inmersos en la "deconstrucción del objeto étnico", hemos criticado las viejas tradiciones esencializadoras para sustituirlas por aproximaciones constructivistas y modelos analíticos que vayan considerando las articulaciones entre cultura, identidad y poder; mientras curiosamente las tecnologías de gobierno y las agencias multilaterales de desarrollo han pretendido desde mediados de 1980 delimitar con precisión los contornos y las naturalezas de los pueblos indígenas de la ecúmene capitalista global. La historia misma de las disciplinas demuestra que el conocimiento no es absoluto y que el contexto histórico como el ejercicio de la profesión producen un condicionamiento primordial entre sí (Uribe y Adán 2003). Al respecto, debemos ser conscientes y explicitar el hecho de que una determinada verdad surge inevitablemente de cuestiones políticas; por lo tanto, el sentido histórico en cuanto abordaje sobre la singularidad de los sucesos, se convierte de manera irremediable en una crítica hacia las significaciones ideales y los indefinidos teleológicos (Foucault 1979). Pues el poder de convencimiento o la verdad de los discursos no emergen como una fuente de legitimación vertical, sino como una energía horizontal mediante la "donación de sentido" que se libera del tejido de relaciones y conflictos en una situación concreta (Marramao 2013: 17). Esto implica aceptar que la historia se ha leído desde el prisma, en este caso, de la nación chilena, peruana, boliviana u otra; y que, por ejemplo, la etnohistoria es otro capítulo más en la narrativa de la dominación global, por lo que se debería generar un "contra-discurso en serio" (Boccara 2013: 528).

La preocupación desde investigadores y académicos por establecer prácticas de difusión del conocimiento obtenido hacia las comunidades locales que incorporan en el presente las distintas visiones sobre el pasado, se establece dentro de un contexto nacional a su vez inmerso en el concierto internacional. Durante el último tercio del siglo XX, las movilizaciones indígenas fueron visibilizando 
la artificiosa dicotomía entre pasado y presente impuesta desde los discursos hegemónicos del Estado, el capital o la ciencia. Las demandas y las reivindicaciones indígenas impactaron fuertemente el devenir del mundo académico, generando una efervescencia crítica y un proceso comprometido con el contexto político que buscaba cuestionar el origen colonial de las disciplinas sociales; de tal manera que la tensión entre investigaciones científicas y comunidades locales refleja a nivel micro el conflicto entre los Estados nacionales y los pueblos originarios (Uribe y Adán 2003). El período de dictaduras en Latinoamérica viene a truncar este ejercicio de la profesión, quedando su práctica entumecida en los fragores del autoritarismo, hasta que las transiciones democráticas permiten retomar este ímpetu con matices propios. En el contexto actual, las fuerzas de la modernidad global exhiben serias contradicciones a partir de la ligadura entre el Estado liberal moderno y la nación multicultural, donde las sociedades poscoloniales se ven obligadas a enfrentar de manera creciente el desafío que plantea la hegemonía de una ley única bajo el signo de la identidad cultural (Comaroff y Comaroff 2013). La prominencia cada vez mayor del plano del derecho genera la judicialización de la política misma; pues, aun cuando la intención es discutir la propia soberanía del Estado, las demandas en torno a las identidades particulares no tienen más remedio que hacerse en términos jurídicos; es decir, en el idioma de los derechos, el constitucionalismo y el debido proceso.

La judicialización de la política y la mercantilización de la cultura dan cuenta del "carácter empresarial" que se les otorga a las cuestiones identitarias en los tiempos del neoliberalismo, a la vez que su dimensión multicultural opera como el mecanismo encubridor por excelencia de las nuevas formas de colonización (Boccara 2013, Comaroff y Comaroff 2011, Rivera Cusicanqui 2010). Es que el multiculturalismo, en tanto proyecto cultural del neoliberalismo, se refiere a las articulaciones entre la economía capitalista y el reconocimiento de algunos derechos colectivos, mediante medidas de tutelaje y restricciones internas; actúa estableciendo espacios de participación y negociación, pero al mismo tiempo limitando y conteniendo las demandas de las pretensiones indígenas. Todo este aparataje funciona sin nunca cuestionar los elementos constitutivos o característicos del Estado neoliberal, pues quien define el límite de lo permitido no es el sujeto que vive esa diferencia, sino quien pretende controlarla.

Es aquí donde se observa la tensa cuerda o la tensión política que divide a las perspectivas funcionales de las posiciones críticas; o como se ha señalado concisamente la distinción entre el "indio permitido" y el "indio subversivo" (Rivera Cusicanqui 2010). El indio se acepta mientras se mueva en torno a las concesiones y las manifestaciones de diversidad circunscritas por el multiculturalismo neoliberal; en cambio, el indio se vuelve subversivo cuando cuestiona el estado imperante de las cosas y se moviliza para cambiarlo, poniendo en jaque la legalidad y la legitimidad del sistema. El interés del mundo académico hacia el diálogo multicultural forma parte de este tipo de debates y paradojas. Las prácticas de devolución del conocimiento generadas desde la universidad frecuentemente son administradas mediante fondos concursables; pero pocas veces integran a otras colectividades mediante una participación conjunta en la producción de saberes, perpetuando la idea de que el conocimiento que da la academia se posiciona por sobre el de la comunidad y su memoria local. Todavía más, nuestro bagaje teórico tiende a otorgarle un estatus privilegiado a la dimensión narrativa por medio de la cual se construye y se transmite un determinado conocimiento, dejando sin consideración o restándole importancia a los aspectos performativos que constituyen el espacio mental y físico desde donde se engarza nuestro entendimiento (Connerton 1989).

En suma, lo que debería importar son las condiciones de producción de las narrativas y la manera cómo el diferencial de poder en el presente determina las representaciones del pasado-historia (Boccara 2013: 528). De acuerdo con el autor, entonces, en la medida en que los "pueblos originarios" emergieron como unos agentes sociales protagónicos de la crítica a la modernidad capitalista, nacional y estatal contemporánea de América Latina, no debería extrañar que sus producciones cuestionen tanto la representación del pasado como los modos de escritura y la formación de identidades sociales, políticas y profesionales en el presente. Pero aún falta mayor vocación de diálogo y más autocrítica desde las disciplinas sociales; pues hemos sido obnubilados por nuestra obsesión de construir una historia verdaderamente científica y en ello hemos descuidado las contradicciones presentes en el espacio plural de las historicidades locales. 


\section{Conclusiones: Apuntes Críticos Sobre un Diálogo en Curso}

Aunque nos moleste la naturalización de la identidad cultural, la ofensiva radical que el imperio del capital plantea contra otros epistemes o el silencioso deterioro de antiguos principios de movilización y acción colectiva; también es preciso abordar y reflexionar en torno a los fenómenos recientes de venta de productos culturales, las etnicidades discursivas, las identidades situacionales, la homogeneidad de algunos relatos sobre las resistencias y los procesos de reconstrucción que se han realizado frente a las grandes lógicas dominantes. El desafío está en develar las prácticas ambiguas y complejas que se corresponden con la actual "política de la identidad" y las historias "alternativas" (Boccara 2013: 528, Comaroff y Comaroff 2011: 96-97); pues resulta paradójico que sea sobre esta misma personería jurídica e ideal, surgida en el marco de una cultura planetaria de lo legal, donde se apoyan las actuales reivindicaciones étnicas y las luchas por recuperar derechos y territorios ancestrales. De tanto desmenuzar teóricamente sobre lo auténtico o lo original de una cultura, hemos olvidado transmitir la compleja situación actual de otredad y la diversidad cultural interna, cuyos linderos se establecen de manera tan ambigua como conflictiva. Le falta más praxis y conocimiento "mestizo" a nuestras disciplinas, según el decir de Arguedas (1977). En un tercer milenio caracterizado por la polarización socioeconómica, la racialización y el mestizaje planetario, donde las brechas han tendido a ensancharse, debemos animarnos a formular nuevas hipótesis acerca de la situación de las sociedades latinoamericanas actuales y nuevas teorías desde el sur sobre la ecúmene capitalista global; cuyos estudios sean llevados a cabo tanto por agentes indígenas como mestizos o foráneos.

$\mathrm{Al}$ respecto, no debemos contentarnos con la simple transvaloración de la dicotomía colonial básica entre nativos y no nativos que se esconde tras el vocablo "indígena"; sino que debemos seguir la teoría y la praxis de los comuneros con relación al problema de la "autenticidad", de cuyos diálogos internos el investigador llega a ser testigo y también partícipe de conversaciones en las cuales su narrativa jamás podrá independizarse (Salomon 2001). De esta manera, interesa que las comunidades demanden activamente la difusión de las investigaciones universitarias con una mayor capacidad de acción colectiva, la que pueda propiciar en la academia una práctica de "cultura de la devolución" o "vuelta de mano". Estas demandas e imprecaciones desde el mundo indígena no solo debieran sustentarse en reclamos o fines utilitarios que inevitablemente se traducirán en relaciones autoritarias, asistencialistas o paternalistas, sino que requieren la construcción permanente de un diálogo recíproco o "colaborativo" (Rappaport y Ramos Pancho 2012). Es decir, donde las ideas indígenas sean tratadas igual que las ideas científicas, según sus respectivas disposiciones para crear conceptos, suscitar consensos y otras historias (Viveiros de Castro 2010). Concordamos con otros autores acerca de que no se ha reflexionado lo suficiente sobre el posicionamiento de nuestras disciplinas en las sociedades latinoamericanas actuales (p.ej., Boccara 2013, Gavilán 2013, Salomon 2001). Creemos que es posible avanzar en esas otras formas de interlocutar con las comunidades desde lugares de enunciación contrahegemónicos y subalternos, que nos permitan repensar las múltiples historicidades para ir generando relacionalidades conscientes de la coproducción de narrativas sobre el pasado en el marco de las luchas de memoria en el presente. Asimismo, si la construcción discursiva posee un carácter eminentemente performativo, debemos ser más cautelosos en torno a los aspectos físicos y dogmáticos de nuestros enunciados, así como ser más responsables acerca de nuestra producción historiográfica en los usos pragmáticos del presente político.

Actualmente, tanto el análisis de los documentos coloniales como los resultados de ciertas investigaciones arqueológicas permiten revitalizar la etnicidad de ciertas poblaciones (p.ej., Ayala 2008, Comaroff y Comaroff 2011, Salomon 2001, Uribe y Adán 2003). Ahora bien, la recepción moderna de los textos antiguos implica una serie de estrategias interpretativas por parte de los comuneros; las cuales no solo se condicionan por las ideas que maneja la comunidad en cuanto al modo "correcto" de lectura, sino también por determinadas nociones de historia general transmitidas oralmente y por la intención del contexto en que se realiza. El intento pragmático de las lecturas en los foros intracomunitarios es, en este sentido, el poder contar con una fuente de legitimidad que pueda incidir jurídicamente y sea capaz de concitar el apoyo de las agencias estatales, las universidades, las organizaciones no gubernamentales y los organismos internacionales en favor de sus pretensiones legales y sus luchas 
políticas. Esta "doctrina de legitimidad" en torno a los documentos coloniales, por ejemplo, supone para los comuneros la necesidad de ser "autóctonos" en cuanto al origen y la organización social; a la vez que "modernos" o "constitucionales" en la forma de manejar legalidades, presentándose como un campesinado progresista en permanente contacto con una tradición oral que incorpora otros modelos mucho más antiguos de la identidad y del cambio (Salomon 2001: 72-73). Así,

"La escritura de las historias de los indígenas ya no puede realizarse sin considerar las historias, memorias y epistemologías alter-nativas [...] Una tarea que implica repensar nuestra institucionalidad científica (sus intereses, valores, enjeux, criterios de evaluación), así como también una redefinición de los mecanismos de autorización y de legitimación de los saberes" (Boccara 2013: 529).

Sin duda, se puede hablar de un compromiso social de las disciplinas académicas hacia el mundo indígena, donde a todas luces la interacción mutua es enriquecedora para ambas partes; pero la realidad es aún más esquiva. Una investigación científica involucrada con la comunidad supondría un relato para destrozar sistemáticamente los postulados objetivos y las totalidades cerradas de la "ciencia", a la vez que obliga a reflexionar sobre el estatus de la producción historiográfica en el presente político. En términos nietzscheanos se trataría de realizar una "historia efectiva" que introduzca lo discontinuo en nuestro ser, de plasmar un "saber en perspectiva" que permita al mismo tiempo la genealogía de los trazos de poder que enmascara todo conocimiento. En oposición a la idea de un pasado inamovible que cuenta el nacimiento de la verdad y del valor, este "sentido histórico" exige la entrada en escena de otras fuerzas y el azar de la lucha; así, el gran juego de la historia en tanto genealogía es quién se amparará de las reglas, quién se disfrazará para pervertirlas y quien las utilizará a contrapelo para dirigirlas contra aquellos que las habían impuesto (Foucault 1979: 22).

De este modo, es que la valoración simultánea otorgada a los libros parroquiales de Belén disfraza una disputa y un desequilibrio; pues el hecho de que ambas partes coincidan en darles un valor a los registros, no significa que la dotación de sentido sea la misma. Estos libros representan ciertos dispositivos de memoria y de poder; entonces, el diálogo horizontal se iniciará en la medida que se expongan los juegos de poder que caracterizan a cualquier conocimiento, lo cual permitirá ir incorporando las prácticas cotidianas y contradictorias que diversos hombres y mujeres han desplegado para sobrevivir. Por ejemplo, enfrentar el racismo, el empobrecimiento y la exclusión social originada en relaciones de colonialismo internalizado. Las versiones vernáculas del pasado no hablan solamente de grandes líderes, de luchas colectivas organizadas al poder o de cosmovisiones cohesionadas; sino que guardan relación con la reconstrucción que puede operar haciendo habitable la vida cotidiana, en aquellas zonas grises donde se expresan las identidades ambiguas y heterogéneas producto de las historias de servidumbre y explotación (Nahuelpán 2013).

Si las narraciones históricas locales o alternativas parecen extrañas, no hay por qué presumir que son menos fundamentadas en la experiencia. Conviene, según plantea Boccara, "asentar una metodología plural que tome en cuenta la diversidad de los conocimientos y de las condiciones históricas de los productores de saberes con el fin de romper con la colonialidad del poder que sigue informando nuestras maneras de hacer ciencias sociales" (2013: 529). Es interesante, por lo tanto, pensar en la comunidad local como una colectividad con funciones autoinvestigativas, la que continuamente estudia sus propios registros escritos; incluso para fines tanto administrativos inmediatos como para objetivos más estratégicos, cuestionando así el presente y analizando las formas de controlar el pasado. Por ello, se vuelve forzoso tomar en serio el panorama histórico conceptualizado desde las poblaciones andinas, lo que se expresaría en una paridad entre las investigaciones universitarias y el autoestudio de las comunidades que asuma la forma bakhtiniana de una polifonía discordante mediante el diálogo vivo, porque "si no permitimos que la etnohistoria strictu sensu rete a la historiografía académica, ésta resulta ser un mero gueto" (Salomon 2001: 78) .

\section{Agradecimientos}

A Xochitl Inostroza y Jorge Hidalgo por la experiencia conjunta y los enriquecedores debates. A Carlos Choque y Cristián Arias por su compromiso y destacada participación en el proyecto como 
representantes de la comunidad. A Juan Chacama quien animadamente nos acompañó en terreno y colaboró con las gestiones en la Universidad de Tarapacá para coordinar nuestra estadía. A Eddie
Zegarra por su cálida hospitalidad y a la gente de Belén por el fructífero diálogo en el taller. También agradecemos los valiosos comentarios de los evaluadores del manuscrito.

\section{Referencias Citadas}

Abercrombie, T.

2006 [1998] Caminos de la memoria y del poder. Etnografía e historia en una comunidad andina. IFEAIEB, La Paz.

Albó, X.

2007 Alcaldes y munícipes indígenas en Bolivia, 2002. En Movimientos indígenas y gobiernos locales en América Latina, editado por W. Assies y H. Gundermann, pp. 89-118. Línea Editorial IIAM, Universidad Católica del Norte, San Pedro de Atacama.

Antileo, E.

2013 Políticas indígenas, multiculturalismo y el enfoque estatal indígena urbano. Revista de Historia Social y de las Mentalidades 17(1): 133-159.

Arguedas, J.M.

1977 Formación de una cultura nacional indoamericana. Selección y prólogo de Angel Rama. Siglo XXI Editores, México DF.

Ayala, $\mathrm{P}$.

2008 Políticas del Pasado. Indígenas, arqueólogos y estado en Atacama. Línea Editorial IIAM, Universidad Católica del Norte, San Pedro de Atacama.

Boccara, G.

2013 La apoteosis de la antropología histórica y el desafío postcolonial. Chungara. Revista de Antropología Chilena 45, 4: 523-5321.

Carrasco, A.M.; V. Gavilán; H. González y H. Gundermann. 1993 La experiencia del Taller de Estudios Andinos (TEA) en la promoción de la producción artesanal, Revista Proposiciones 23: 397-424.

Comaroff, J. y J. Comaroff. 2011 Etnicidad S.A. Katz, Buenos Aires.

Comaroff, J. y J. Comaroff.

2013 Teoría desde el sur. O cómo los países centrales evolucionan hacia África. Siglo Veintiuno, Buenos Aires.

Connerton, $\mathrm{P}$.

1989 How societies remember. University Press, Cambridge.

Chatterjee, $\mathrm{P}$.

2008 La nación en tiempo heterogéneo y otros estudios subalternos. Siglo Veintiuno, Buenos Aires.

Choque, C.

2012 Se van los peruanos... los más testarudos se quedan: memorias y olvidos de la chilenización en Socoroma. Tesis para optar al Grado de Doctor en Antropología, Pontificia Universidad Católica del Perú, Lima.

Díaz, A.; L. Galdames y R. Ruz.

2010 "Nación e identidad en los Andes indígenas de Arica y Estado chileno (1883-1929)". Ediciones Universidad de Tarapacá, Arica.

Fanon, F.

2003 [1973] Los condenados de la tierra. Fondo de Cultura Económica, México DF.
Foucault, M.

1979. Microfísica del Poder. Ediciones de la Piqueta, Madrid.

Galdames, L. y A. Díaz.

2007. La construcción de la identidad ariqueño-chilena durante las primeras décadas del siglo XX". Revista Diálogo Andino 29: 19-28.

Gavilán, V.

2013 De la administración de poblaciones y de etnicidades en los Andes del sur: Las dos caras de la colonización ayer y hoy. Revista Chilena de Antropología 45(4): 543-551.

González, H.; H. Gundermann y J. Hidalgo.

2014 Comunidad indígena y construcción histórica del espacio entre los aymaras del norte de Chile. Chungara. Revista Chilena de Antropología 46(2): 233-246.

Inostroza, X; C. Choque; F. Urrutia; J. Hidalgo; M. Uribe y C. Arias

2014 Libros de la parroquia de Belén: Historia y memoria. En Coyunturas Pasadas y Presentes de los Pueblos Originarios, editado por A. Cornejo y S. Montecino, pp. 113-135. Editorial Catalonia, Santiago.

Mamani, C.

2007 Memoria y reconstitución. En Intelectuales Indígenas piensan América Latina, compilado por C. Zapata, pp. 285310. Ediciones Abya-Yala, Quito.

Marramao, G.

2013 Contra el poder. Filosofía y escritura. Fondo de Cultura Económica, Buenos Aires.

Moraga, C.; J. Aguilar y A. Díaz.

2010 Litigar y conservar. Política colonial y pleitos por tierra en San Antonio de Mocha (Tarapacá), 1760-1787. Revista Diálogo Andino 36: 79-117.

Nahuelpán.

2013 Las zonas grises de las historias mapuche. Colonialismo internalizado, marginalidad y políticas de la memoria. Revista de Historia Social y de las Mentalidades 17(1): 11-33.

Quijano, A.

2000 Colonialidad del poder, eurocentrismo y América Latina. En La colonialidad del saber: eurocentrimo y ciencias sociales. Perspectivas latinoamericanas, editado por E. Lander, pp. 201-246. CLACSO, Buenos Aires.

Rivera Cusicanqui, S.

2010 Ch'ixinakax utxiwa: una reflexión sobre prácticas y discursos. Editorial Tinta Limón, La Paz.

Rappaport, J. y A. Ramos Pacho.

2012 Collaboration and Historical Writing: Challenges for the Indigenous-Academic Dialogue. En Decolonizig Native Histories, editado por F. Mallon, pp. 122-143. Duke University Press, Durham and London.

Ruz, R.; A. Díaz y L. Galdames.

2008 Población andina de las provincias de Arica y Tarapacá. El censo inédito de 1866. Ediciones Universidad de Tarapacá, Arica. 
Salomon, F.

2001 Una historia poco étnica. Nociones de lo autóctono en una comunidad campesina peruana. Desacatos 7: 65-84.

Salomon, F.

2013 Supermán es más supermán cuando se quita la malla. Chungara. Revista de Antropología Chilena 45(4): 515-522.

Uribe, M. y L. Adán. 2003. Arqueología, poblaciones originarias y patrimonio cultural en el Desierto de Atacama. Chungara. Revista de Antropología Chilena 35(2): 295-304.
Urrutia, F.

2011 Participación Social en la Quebrada de Camiña: Entre los Avatares de la Tradición y la Dinámica Municipal. Tesis para optar al Título de Antropología, Mención Antropología Social, Facultad de Ciencias Sociales, Universidad de Chile, Santiago.

Viveiros de Castro, E.

2010 Metafísicas caníbales. Líneas de antropología postestructural. Katz, Buenos Aires.

\section{Notas}

1 Financiado por la Vicerrectoría de Extensión de la Universidad de Chile, mediante el fondo U-Cátedra Indígena y contó con el patrocinio del Archivo Nacional de Chile. El proyecto nació de la investigación doctoral de Xochitl Inostroza, quien utilizó como fuente principal los registros de bautizo, matrimonio y defunciones de la parroquia de Belén (1763-1859). El proyecto se desarrolló durante el año 2013 y participaron en él los académicos Jorge Hidalgo del Departamento de Ciencias Históricas, Mauricio Uribe del Departamento de Antropología, Xochitl Inostroza del programa Doctorado en Historia mención Etnohistoria y Francisca Urrutia, antropóloga egresada de la Universidad de Chile. Además se incorporaron al equipo en calidad de representantes de la comunidad de Belén, el Dr. Carlos Choque, egresado de la Pontificia Universidad Católica del Perú y vecino del poblado de Socoroma, así como Cristián Arias, estudiante del programa de Licenciatura en Historia y Ciencias Sociales de la Universidad de Tarapacá, quien es descendiente de habitantes de Belén. Las piezas documentales que se realizaron durante el proyecto estuvieron a cargo de Carlos Saavedra, académico de la carrera de Cine y Televisión de la Universidad de Chile, en los que participaron Pablo Pinto, Patricio Alfaro y Valentina León.

2 La tesis de Xochitl Inostroza se titula "Parroquia de Belén: Reconstitución de familias, redes y pueblos", conducente al grado de Doctor en Historia mención Etnohistoria, dirigida por el Dr. Jorge Hidalgo como profesor guía.

3 La actividad fue organizada por la Vicerrectoría de Extensión de la Universidad de Chile. Esta tenía por objetivo realizar charlas en diferentes escuelas del país sobre investigaciones en curso dentro de la universidad. Contamos además con el apoyo del Consejo Nacional de la Cultura y las Artes de la Región de Arica y Parinacota; por lo que agradecemos especialmente la colaboración de su directora Patricia Arévalo.
4 Disponible tanto en la biblioteca de la Facultad de Filosofía y Humanidades como en la Facultad de Ciencias Sociales de la Universidad de Chile.

5 Hemos optado por mantener los nombres propios pertenecientes al habla de la comunidad, señalando de antemano que hubo consentimiento de consignar sus opiniones en el marco de los vínculos y las reflexiones para un diálogo entre las investigaciones universitarias y las comunidades locales. Así como existe rigurosidad para individualizar ciertas ideas científicas y contextualizarlas dentro de un campo teórico, creemos que en esta ocasión resulta pertinente consignar de manera parecida a las ideas beleneñas. Nuestra intención es que el relato pueda asumir la forma de una vasta y franca conversación donde los significados se acoplan en un diálogo mediante distintos espacios de enunciación que rebasa la autosuficiencia y la unilateralidad de cada uno.

6 Presidente de la Junta de Vecinos y la Comunidad de Belén, encargado del Registro Civil y miembro del Consejo Nacional Aymara por la comuna de Putre.

7 Una muestra elocuente fue la solicitud que se le hizo al Dr. Jorge Hidalgo para que expusiera su conocimiento sobre el pasado de Belén; lo cual constató la valoración y el reconocimiento a su larga trayectoria académica, así como también la importancia otorgada hacia las investigaciones etnohistóricas y arqueológicas en la construcción de la memoria andina.

8 Estos avatares no son exclusivos del mundo indígena; por el contrario, constituyen una visión fractal de esa "identidad-empresa" que se ha cristalizado en tiempos del neoliberalismo, trocando como rey Midas a la cultura en etnomercancía, a la nación en "marca-país", a las preocupaciones existenciales del ser social en "Divinidad S.A." (Comaroff y Comaroff 2011).

9 Ponencia presentada en las Primeras Jornadas de Etnohistoria, Historia Indígena y Antropología. Universidad de Chile, Santiago de Chile. 2013. 